\title{
miR-367-3p downregulates Rab23 expression and inhibits Hedgehog signaling resulting in the inhibition of the proliferation, migration, and invasion of prostate cancer cells
}

\author{
WEI DU ${ }^{1,2}$, DONG LI ${ }^{3,4}$, JIANHAO XIE ${ }^{5}$ and PING TANG ${ }^{1,6}$ \\ ${ }^{1}$ Department of Urology, The First Affiliated Hospital of Jinan University, Guangzhou, Guangdong 510630; \\ ${ }^{2}$ Department of Urology, Guangdong Provincial Hospital of Integrated Traditional Chinese and \\ Western Medicine, Foshan, Guangdong 528200; ${ }^{3}$ Department of Urology, Nanhai Hospital of \\ Guangdong Provincial People's Hospital, Foshan, Guangdong 528251; ${ }^{4}$ Department of Urology, \\ Guangdong Provincial People's Hospital, Guangzhou, Guangdong 510080; ${ }^{5}$ Department of Clinical Laboratory, \\ Nanhai Hospital of Guangdong Provincial People's Hospital, Foshan, Guangdong 528251; ${ }^{6}$ Department of Urology, \\ Guangzhou First People's Hospital, Guangzhou Medical University, Guangzhou, Guangdong 510180, P.R. China
}

Received July 16, 2020; Accepted April 2, 2021

DOI: $10.3892 / o r .2021 .8143$

\begin{abstract}
MicroRNAs play an important role in tumor cell proliferation, invasion, and Rab23 is a member of the Ras-related small GTPase family and plays a critical role in the progression of may types of tumors. The present study was designed to investigate the inhibitory effect of microRNA (miR)-367-3p on the proliferation, invasion, and metastasis of prostate cancer cells. qRT-PCR was used to detect the expression of miR-367-3p in prostate cancer and adjacent tissues. Cell proliferation, scratch, and Transwell assays were performed to verify the inhibitory effect of miR-367-3p overexpression or Ras-related protein Rab 23 (Rab23) knockdown on prostate cancer. Double luciferase reporter assay was utilized to verify whether miR-367-3p could target the Rab23 3'-untranslated region (UTR). The expression levels of Rab23, Gli1, and Gli2 in prostate cancer cells transfected with the miR-367-3p mimic were detected via qRT-PCR analysis. miR-367-3p expression in the prostate cancer tissues was downregulated compared with that in the para-cancer control tissues. miR-367-3p expression in DU145 and PC3 cells was also downregulated compared with that in the human prostate epithelial cell line RWPE-1. The overexpression of miR-367-3p or the knockdown of Rab23 inhibited the proliferation, invasion, and metastasis of prostate cancer cells. The results of the luciferase reporter assay confirmed that Rab23 was a target gene that was regulated by miR-367-3p. miR-367-3p specifically bound to the 3'-UTR of
\end{abstract}

Correspondence to: Dr Ping Tang, Department of Urology, Guangzhou First People's Hospital, Guangzhou Medical University, 1 Panfu Road, Yuexiu, Guangzhou, Guangdong 510180, P.R. China E-mail: tangping1118156@163.com

Key words: prostate cancer, miR-367-3p, Rab23, Hedgehog, cell proliferation
Rab23 mRNA. The overexpression of miR-367-3p inhibited Rab23 expression and the Hedgehog pathway. Cell function experiments confirmed that the overexpression of Rab23 reversed the anticancer effect of miR-367-3p. miR-367-3p was able to inhibit the Hedgehog pathway by targeting the expression of the Rab23 gene, thus inhibiting the proliferation, invasion, and metastasis of prostate cancer cells.

\section{Introduction}

Prostate cancer is one of the most common malignant neoplasms in the male genitourinary system $(1,2)$. Current treatments for prostate cancer include surgical resection, chemoradiotherapy, and endocrine therapy $(3,4)$. However, advanced metastatic prostate cancer patients treated by these methods still have a poor prognosis and are prone to relapse. Moreover, they tend to show resistance to radiation and chemotherapy drugs (5-7). Therefore, studying the pathogenesis of prostate cancer and identifying key drug targets are urgent concerns $(8,9)$.

MicroRNAs (miRNAs/miRs) are a class of single-stranded noncoding RNAs 18-25 nucleotides long $(10,11)$. miRNAs play an important role in tumor cell proliferation, apoptosis, metastasis, invasion, and drug resistance (12). Current preliminary studies have found that miR-367-3p-5p plays an important role in the occurrence and development of many types of tumors $(13,14)$. miR-367-3p can act as a tumor-suppressor gene and participate in cell proliferation, migration, and apoptosis. However, the specific mechanism of these actions is unknown.

The Ras superfamily of small GTPases includes more than 60 different proteins. Rab is the largest member of the Ras superfamily (15). Studies suggest that Rab23 regulates endosomal pathways that are related to the biogenesis of lysosomal-related organelles (15-17). Rab23 may also play a role in in vivo transport and mitochondrial dynamics (18). Rab23 controls mitochondrial division by interacting with the mitochondrial fission factor Drp1 $(19,20)$ and alters mitochondrial morphology, thus promoting the necrosis or apoptosis 
of primary neurons (21). However, the role of Rab23 in the development of prostate cancer has rarely been reported. The discovery of the Hedgehog/Gli signaling pathway began with the development of Drosophila embryos. Its function involves cell proliferation and differentiation and tissue development. Numerous studies have shown that this pathway is associated with a variety of tumors, including lung, breast, and prostate cancers. Inhibition of this pathway may be a new target for tumor prevention and treatment.

Rab23, a key tumor-related protein, is closely related to the growth activity of prostate cells $(22,23)$. However, whether miR-367-3p can target the expression of the Rab23 gene and affect the proliferation, invasion, and migration of prostate cancer cells has not yet been reported. In this study, bioinformatics and molecular biology techniques were used to investigate the biological functions and molecular mechanisms of miR-367-3p in the occurrence and development of prostate cancer. This study provides a scientific basis for the development of drugs targeting miR-367-3p for the treatment of prostate cancer.

\section{Materials and methods}

Patient tissue collection. Prostate cancer tissues and para-cancer tissues ( $>2 \mathrm{~cm}$ from the surgical edge) confirmed by pathology after urologic surgery at The First Affiliated Hospital of Jinan University from September 2018 to March 2020 were selected. All 10 patients were pathologically confirmed and were not previously treated with chemoradiotherapy. Benign prostatic hyperplasia and other urinary problems were ruled out. Pathological grading was based on Gleason scoring in accordance with the World Health Organization histopathological classification standard for prostate cancer $(24,25)$. Among the samples, 10 were from cases of prostate cancer and 10 were from adjacent tissues. All tissues were stored in a refrigerator at $-80^{\circ} \mathrm{C}$. The patients ranged in age from 49 to 73 years with an average age of $62.3 \pm 8.9$ years. This study was performed at The First Affiliated Hospital of Jinan University and approved by the Ethics Committee of The First Affiliated Hospital of Jinan University. It was in line with the Declaration of Helsinki. All patients provided signed informed consent.

Cell culture. Human prostate cancer cell lines BPH-1, DU145, PC3, TRAMP-C2, and normal prostate cell line (RWPE-1) were purchased from the American Type Culture Collection (ATCC, Washington, DC, America). The cells were cultured in RPMI-1640 medium containing 10\% fetal bovine serum (FBS) (Gibco; Thermo Fisher Scientific, Inc.) and incubated in an incubator (Thermo Fisher Scientific, Inc.) at $37^{\circ} \mathrm{C}$ with $5 \% \mathrm{CO}_{2}$. The cell culture was digested with $0.25 \%$ trypsin. After counting and digestion, cells in logarithmic growth phase were inoculated into a 6 -well plate at the density of $2 \times 10^{5}$ cells per well.

Cell transfection. The cells were transfected with miR-367-3p mimics and mimic-NC (NC: Non-targeting), and were divided into the miR-367-3p mimic group (miR-367-3p upregulated group, 5'-UAGCUUAUCAGACUGAUGUUG A-3' and 5'-AACAUCAGUCUGAUAAGCUAUU-3') and mimic-NC control group (NC, 5'-UUCUCCGAACGUGUC
ACGUTT-3' and 5'-ACGUGACACGUUCGGAGAATT-3'). Meanwhile, the cells were transfected with miR-367-3p inhibitor and inhibitor NC, which were divided into the miR-367-3p inhibitor group (the group with downregulated miR-367-3p expression, 5'-UCAACAUCAGUCUGAUAA GCUA-3') and inhibitor NC control group (5'-GUGGAUAUU GUUGCCAUCA-3'). In addition, the cells were also transfected with si-NC, si-Rab23, vector-NC and vector-Rad23. Transient transfection of cells was performed according to the instructions for Lipofectamine 2000 (Thermo Fisher Scientific, Inc.). After transfection, cell RNA and proteins were extracted for real-time quantitative PCR (qPCR) and western blot experiments.

BrdU experiment. The prostate cancer cells were inoculated into a 12-well plate. A day later, BrdU was added at a concentration of $10 \mu \mathrm{M}$. The experiment was performed $24 \mathrm{~h}$ later. The cells were washed with PBS three times for $3 \mathrm{~min}$ each time and fixed with $4 \%$ paraformaldehyde for $20 \mathrm{~min}$. The cells were washed with PBS three times for 3 min each time. $\mathrm{HCl}(2 \mathrm{M})$ was added at $37^{\circ} \mathrm{C}$ for $30 \mathrm{~min}$. The cells were washed three times with $0.1 \mathrm{~mol} / 1$ boric acid solution and then passed through a Triton X-100 permeable membrane for $20 \mathrm{~min}$. The cells were blocked with $5 \%$ BSA serum at $37^{\circ} \mathrm{C}$ for $30 \mathrm{~min}$. BrdU primary antibody was added at the dilution of $1: 1,200$. The cells were incubated at $4^{\circ} \mathrm{C}$ overnight, mixed with red fluorescent secondary antibody (1:200), and incubated for $45 \mathrm{~min}$. They were stained with DAPI for $1 \mathrm{~min}$. An anti-quenching agent was added to block the plate. The cells were imaged and counted under a fluorescence microscope (magnification, x200, Nikon, Japan).

Wound healing assay. Vertical wounds were scratched into prostate cancer cells by using a $100-\mu 1$ pipette tip. The cell culture medium was discarded. The wounded plate was flushed with PBS three times. After the scratch, the cells were cultured in serum-free medium. The cultured cells were photographed at 0 and $24 \mathrm{~h}$. Image Pro PLUS 6.0 software (Media Cybernetics) was used to analyze and calculate the cell migration distance (26). The migration distance of each group was represented by the ratio of the migration distance and original scratch distance (9).

Transwell experiment. Cells were selected from each group $48 \mathrm{~h}$ after transfection. After trypsin digestion, Matrigel-Transwell chambers (Millipore, USA) were inoculated with $5 \times 10^{4}$ cells per well (27). Serum-free DMEM medium was used for culture in the laboratory. A total of $500 \mu 1$ of $10 \%$ FBS culture medium was added to the lower chamber. After $24 \mathrm{~h}$, the upper layer without invaded cells was wiped with a cotton swab and fixed with $4 \%$ poly(methanol) (Sigma-Aldrich; Merck KGaA) for $15 \mathrm{~min}$. The invasive cells were stained with $1 \%$ crystal violet for $5 \mathrm{~min}$ and washed with PBS for three times. Five fields were randomly selected under a Nikon Eclipse TE2000-U fluorescence microscope (magnification, x100, Nikon) to observe and count and record the number of invasive cells.

Double luciferase reporter gene. The target gene of Rab23 for miR-367-3p was predicted by using TagetScan (http://www. 
targetscan.org/vert_71/) bioinformatics software. The Rab23 mRNA 3'-untranslated region (UTR) fragment containing the miR-367-3p binding site and the Rab23 3'-UTR mutation fragment mutated at the miR-367-3p binding site were cloned into pmIR-Reporter Luciferase Vector (designed by Shanghai Gemma Biological Co.). The recombinant plasmids were named Rab23-WT and Rab23-MUT. DU145 cells in the logarithmic growth phase were collected and inoculated into a 6-well plate at a density of $1 \times 10^{6}$ cells per plate. After $90 \%$ cell confluence, the miR-367-3p mimic and recombinant plasmid were cotransfected with Lipofectamine ${ }^{\mathrm{TM}} 2000$ for backup in accordance with the manufacturer's specifications (Invitrogen; Thermo Fisher Scientific, Inc.). After cotransfection for $24 \mathrm{~h}$, reporter cell lysis buffer was added for $10 \mathrm{~min}$ at room temperature in accordance with the instructions of the dual-luciferase reporter assay kit. A total of $50 \mu \mathrm{l}$ of firefly luciferase assay reagent was added. Relative light units (RLUs) were detected after blending. After $10 \mathrm{~min}, 100 \mu \mathrm{l}$ of Renilla luciferase assay reagent was added. The RLU of the internal reference plasmid pRL-TK was measured after blending, and relative luciferase activity was calculated.

$q R T-P C R$. The mirVana miRNA separation kit and the TaqMan miRNA kit were purchased from Applied Biosystems. Reverse transcription kits (Prime Script ${ }^{\mathrm{TM}}$ RT Reagent Kit with gDNA Eraser) and real-time PCR kits (SYBR Premix II ExTaq ${ }^{\mathrm{TM}}$ ) were procured from TaKaRa (Japan). After digestion and counting, well-grown cells were inoculated into a $10-\mathrm{cm}$ Petri dish at the density of $1 \times 10^{6}$ cells per plate and incubated at $37^{\circ} \mathrm{C}$ and $5 \%$ $\mathrm{CO}_{2}$ under saturated humidity. The cells were collected when their confluence reached $90 \%$. The SYBR Green II fluorescent dye method and an IQ5 ${ }^{\mathrm{TM}}$ Real-Time PCR Detection System (Bio-Rad Laboratories, Inc.) were used for data analysis. The primer sequences were as follows: U6 F, 5'-CACTGTTCCACC CCTCAGAGC-3' and R, 5'-GCCACTTGTCGGCGATAA GG-3' and GAPDH F, 5'-ATATCGCTGCGCTGGTCGTC-3' and $\mathrm{R}, 5^{\prime}$-AGGATGGCGTGAGGGAGAsGC-3'. The reaction conditions were $94^{\circ} \mathrm{C}(15 \mathrm{~min}), 94^{\circ} \mathrm{C}(30 \mathrm{sec}), 60^{\circ} \mathrm{C}(30 \mathrm{sec})$, and $72^{\circ} \mathrm{C}(30 \mathrm{sec})$ for a total of 40 cycles with a final extension at $72^{\circ} \mathrm{C}$ for $8 \mathrm{~min}$. miRNA results for U6 were corrected. Rab23 mRNA expression was corrected on the basis of GAPDH expression. Relative expression was determined through the $2^{-\Delta \Delta \mathrm{Cq}}$ method (28). Three independent replications were conducted.

Western blot analysis. The cells were collected through centrifugation and resuspended with RIPA $(50 \mathrm{mmol} / \mathrm{l}$ Tris- $\mathrm{HCl}, \mathrm{pH} 7.5,150 \mathrm{mmol} / \mathrm{l} \mathrm{NaCl}, 1 \% \mathrm{NP}-40,0.5 \%$ sodium deoxycholate, and $0.1 \%$ SDS). They were ultrasonicated at $12,000 \mathrm{r} / \mathrm{min}$ and centrifuged at $4{ }^{\circ} \mathrm{C}$ for $10 \mathrm{~min}$. Total protein concentration was determined in accordance with the instructions of the BCA kit. SDS-PAGE was performed with $30 \mu \mathrm{g}$ of each sample. Protein was transferred to a PVDF membrane and blocked with $5 \%$ skimmed milk at room temperature for $1 \mathrm{~h}$. The samples were incubated with the primary antibodies of Gli1 (ab217326, 1:1,000 dilution; Abcam), Gli2 (ab277800, 1:1,000, Abcam), and Rab23 (ab230200, 1:1,000, Abcam) separately. GAPDH was used as an internal reference. The samples were kept at $4^{\circ} \mathrm{C}$ overnight. The membranes were washed with TBST and incubated with secondary horseradish peroxidase-conjugated antibody for $1 \mathrm{~h}$ at room temperature. Relative protein expression after ECL development was analyzed by using QuantityOne software (v4.6.7) (Bio-Rad Laboratories, Inc.) after internal reference correction.

Immunohistochemical analysis. The tumor tissues were fixed with $40 \%$ formalin (volume fraction). The tissues (approximately $2-\mathrm{mm}$ in thickness) were cut into the appropriate sizes, embedded, and microwaved with citrate buffer $(\mathrm{pH}=6.0)$ for antigen repair. The tissues were blocked with normal goat serum for $20 \mathrm{~min}$ and incubated overnight with the primary antibody (Rab23, ab230200, 1:100 dilution; Abcam) at $4^{\circ} \mathrm{C}$ then with the corresponding secondary antibody. The samples were then subjected to DAB color development treatment, hematoxylin redyeing, dehydration, and sealing.

Xenograft model. A total of 12 male SPF-grade BALB/C nude mice with weights of 15-20 g/mouse and ages of 4-6 weeks were used in the experiment. Six mice in each group were inoculated with PC3-miR-NC and PC3-miR-367 prostate cancer cells under the armpit at the injection volume of approximately $0.2 \mathrm{ml} /$ piece. The animal experiments were performed in Feb. 2019. The tumor volume was measured with a micron caliper when the tumor became visible $\left(100 \mathrm{~mm}^{3}\right)$ after inoculation. The living conditions of nude mice were observed daily. The length and width of the tumor were measured. All nude mice were sacrificed at the end of the third week of the experiment. Euthanasia method was as follows. The mice were put into a euthanasia chamber without pre-filled $\mathrm{CO}_{2}$. Next, the cylinder was opened and $100 \%$ carbon dioxide was added. The filling rate was about $15 \% \mathrm{CO}_{2} / \mathrm{min}$ of the chamber volume. After $10 \mathrm{~min}$, the nude mice were examined for death. The surviving mice continued to be treated with $\mathrm{CO}_{2}$ for 5 mins. When the animals were determined to be not moving, breathing, and the pupils were dilated. The $\mathrm{CO}_{2}$ was closed and another $2 \mathrm{~min}$ passed to confirm the animal death. The exfoliated transplanted tumor was weighed. And the maximum diameter of the tumor tissue we observed was no more than $1.3 \mathrm{~cm}$. Tumor volume (TV) was calculated in accordance with the following formula: TV $\left(\mathrm{mm}^{3}\right)=0.5 \times$ long diameter $(\mathrm{mm}) \times$ short diameter ${ }^{2}$ $\left(\mathrm{mm}^{2}\right)$. Experimental animal welfare followed the guidelines for Welfare Ethics Review (GB/T 35892-2018). Animal experiments were approved by the Ethics Committee of The First Affiliated Hospital of Jinan University (Guangzhou, Guangdong, China) (no. IRB-JN-2019-023).

Statistical analysis. Each experiment was repeated independently three times. SPSS 17.0 statistical software (SPSS Inc.) was used to analyze relevant data (29). The results are expressed as mean $\pm \mathrm{SD}$. Comparison between groups was performed by the unpaired Student's t-test. One-way ANOVA followed by Tukey's multiple comparison tests were selected for multiple group comparisons. Pearson correlation coefficient was used to analyze coexpression correlation. Here, $\mathrm{P}<0.05$ was indicative of a statistically significant result (30).

\section{Results}

miR-367-3p is downregulated in prostate cancer. The role of miR-367-3p in prostate cancer can be inferred by detecting its expression level. We collected 10 pairs of prostate cancer tumor tissues and adjacent control tissues. The expression of miR-367-3p was detected through qRT-PCR. The experimental 
A

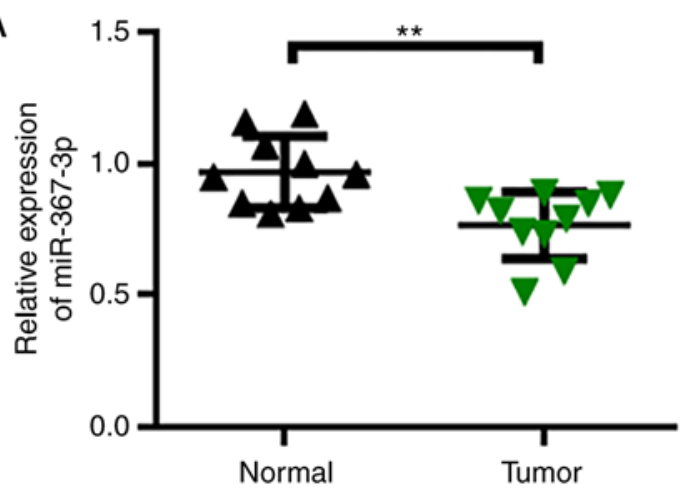

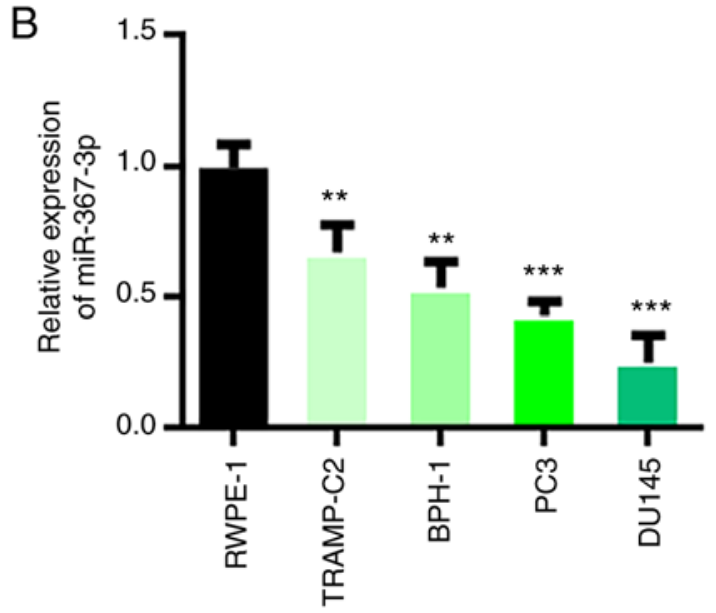

Figure 1. miR-367-3p is downregulated in prostate cancer. (A) miR-367-3p expression was detected via RT-qPCR in 10 normal and 10 prostate cancer tissues. (B) Detection of miR-367-3p expression in human normal prostate epithelial cells (RWPE-1) and prostate cancer cells (BPH-1, DU145, PC3, and TRAMP-C2). ${ }^{* *} \mathrm{P}<0.01,{ }^{* * *} \mathrm{P}<0.001$.

results showed that miR-367-3p expression in prostate cancer tumor tissues was downregulated relative to that in the adjacent control tissues (Fig. 1A). Furthermore, the expression levels of miR-367-3p in normal human prostate epithelial cells (RWPE-1) and prostate cancer cells (TRAMP-C2, BPH-1, PC3, and DU145) were analyzed. The experimental results showed that compared with that in RWPE-1 cells, miR-367-3p expression in BPH-1, DU145, PC3, and TRAMP-C2 cells was downregulated and was the lowest in the DU145 and PC3 cells (Fig. 1B). Therefore, the PC3 and DU145 cells were selected for subsequent experiments.

Overexpression of $m i R-367-3 p$ inhibits the malignant evolution of DU145 and PC3 in prostate cancer. After analyzing the expression level of miR-367-3p in prostate cancer tissues and cell lines, the effects of miR-367-3p on the malignant evolution of prostate cancer cells were evaluated through cell proliferation, wound healing and Transwell assays. First, we measured the expression efficiency of miR-367-3p in DU145 and PC3 cells. The experimental results showed that miR-367-3p mimics upregulated the expression of miR-367-3p, whereas the miR-367-3p inhibitor inhibited the expression of miR-367-3p (Fig. 2A and B). Subsequently, the proliferation capability of the cells was measured via the BrdU assay. The experimental results showed that the overexpression of miR-367-3p inhibited the proliferation of DU145 and PC3 cells, whereas the inhibition of miR-367-3p enhanced the proliferation of DU145 and PC3 cells (Fig. 2C and D).

Overexpression of miR-367-3p inhibits the migration, invasion and proliferation. We performed wound healing experiments to evaluate the migratory capability of prostate cancer cells. The results showed that the overexpression of miR-367-3p inhibited the migration of DU145 and PC3 cells, whereas the inhibition of miR-367-3p increased the migration of DU145 and PC3 cells (Fig. 3A and B). Subsequently, we performed the invasion assay to evaluate the invasive capability of prostate cancer cells. We found that the invasive capability of the DU145 and PC3 cells in the miR-367-3p mimic group was significantly lower than that in the blank control group. Compared with that of the cells in the inhibitor group, the invasion capability of DU145 and PC3 cells in the miR-367-3p inhibitor group was enhanced (Fig. 3C and D). We performed animal experiments to verify the antitumor effect of miR-367-3p. The results of the animal experiments showed that miR-367-3p inhibited tumor growth and reduced tumor weight (Fig. 3E).

Rab23 may be a target of $m i R-367-3 p$. We used TargetScan to predict the target genes of miR-367-3p to investigate the function of miR-367-3p. The prediction results showed that Rab23 may be a target gene of miR-367-3p. Fig. 4A shows the binding site information of Rab23 and miR-367-3p. We conducted the luciferase reporter gene experiment to further verify our conjecture in DU145 cell lines. The experimental results showed that luciferase activity in the miR-367-3p mimic + Rab23-WT (wild-type) group was lower than that in the mimic-NC + Rab23-WT group. However, after the mutation of the Rab23 binding site, the miR-367-3p mimics could no longer inhibit the luciferase activity of Rab23 (Fig. 4B). The qRT-PCR results showed that Rab23 expression in the miR-367-3p mimic group was significantly decreased compared with that in the miR-NC group. However, Rab23 expression was significantly upregulated in the miR-367-3p inhibitor group (Fig. 4C). Furthermore, we analyzed the expression level of Rab23 in prostate cancer tissues. The experimental results showed that Rab23 was upregulated in the prostate cancer tissues (Fig. 4D). In addition, we quantified the expression of Rab23 in the para-cancer control and tumor tissues. Our immunohistochemical test results showed that Rab23 was highly expressed in the prostate cancer group relative to that in the control group (Fig. 4E). miR-367-3p and Rab23 coexpression levels were highly and negatively correlated (Fig. 4F).

Rab23 knockdown inhibits the malignant evolution of prostate cancer cells. We studied the effect of Rab23 on the malignant evolution of prostate cancer cells through Transwell, wound healing, and cell proliferation assays. First, the expression efficiency of Rab23 in DU145 and PC3 cells was detected. 
A

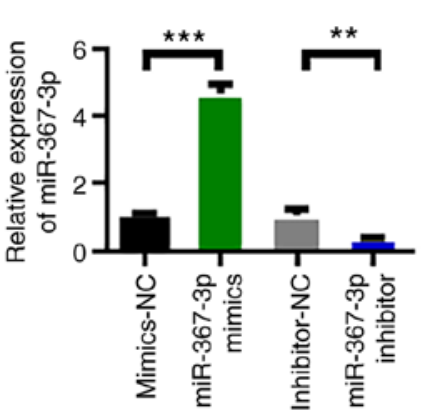

B

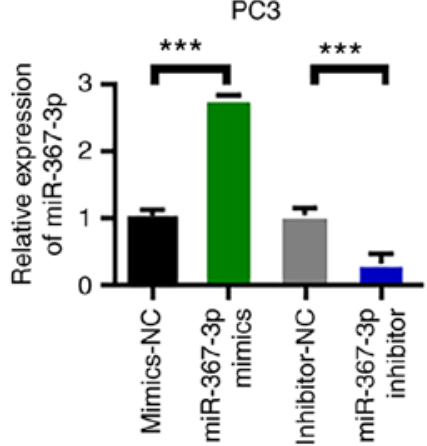

C
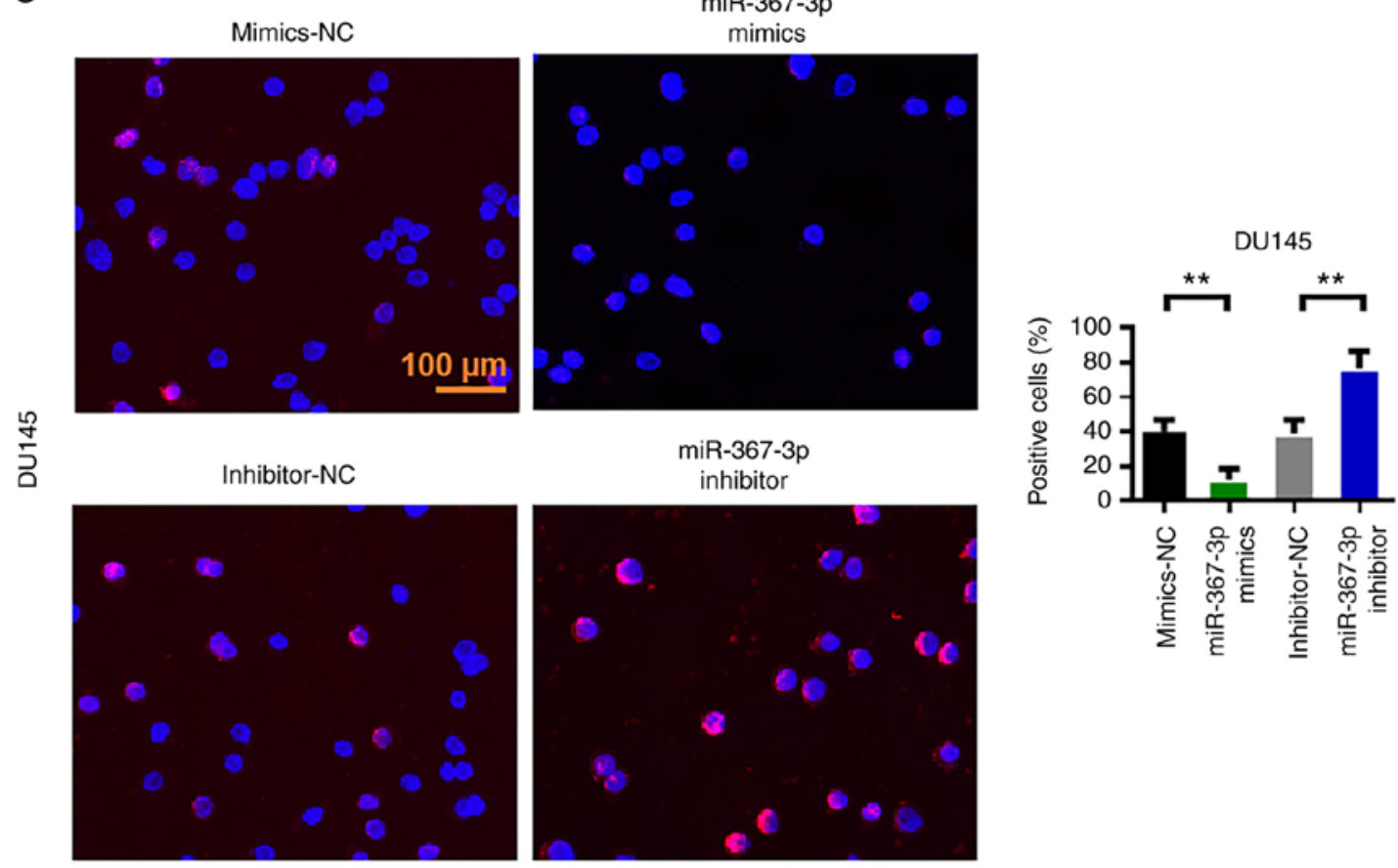

D

Mimics-NC

miR-367-3p
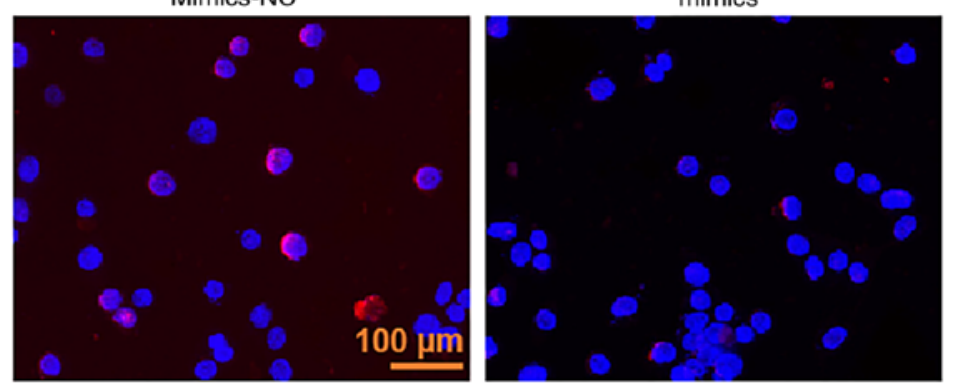

\%

Inhibitor-NC

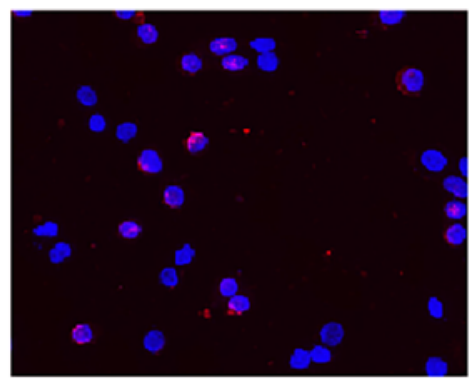

miR-367-3p
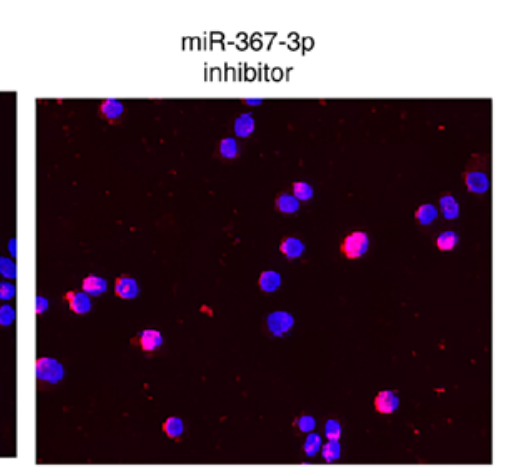

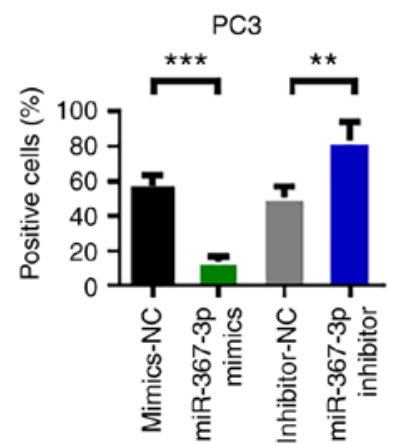

Figure 2. Overexpression of miR-367-3p inhibits the malignant evolution of prostate cancer DU145 and PC3 cells. (A) Detection of miR-367-3p expression efficiency in DU145 cells transfected with the miR-367-3p mimic and inhibitor. (B) Detection of the expression of miR-367-3p in PC3 cells transfected with the miR-367-3p mimic and inhibitor and the relevant controls. (C) DU145 cell proliferation via the BrdU assay. (D) PC3 cell proliferation via the BrdU assay. Magnification, $\mathrm{x} 200 .{ }^{* *} \mathrm{P}<0.01,{ }^{* * * *} \mathrm{P}<0.001$. 
A
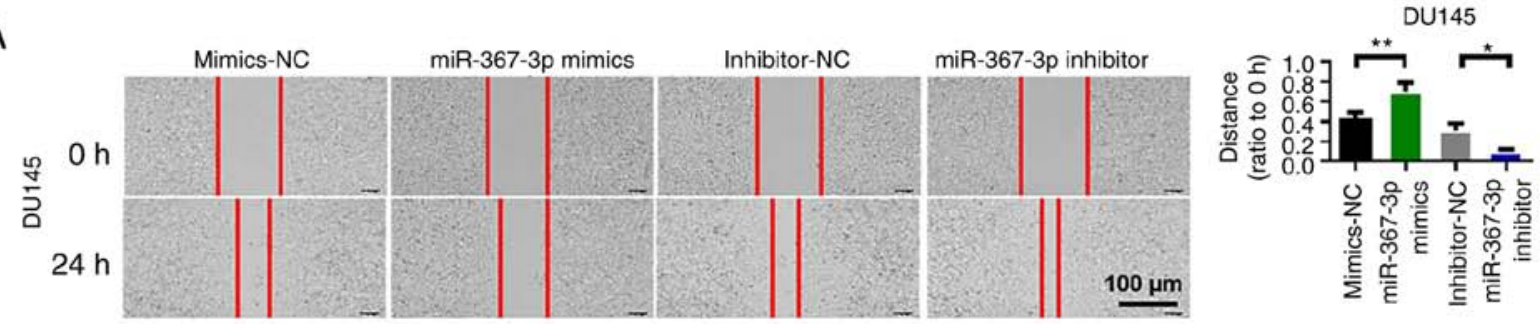

B
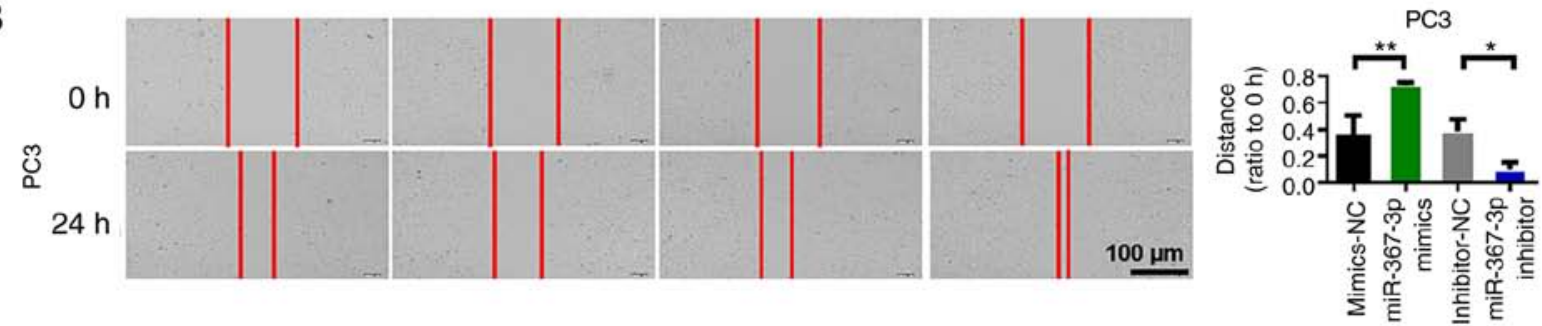

C

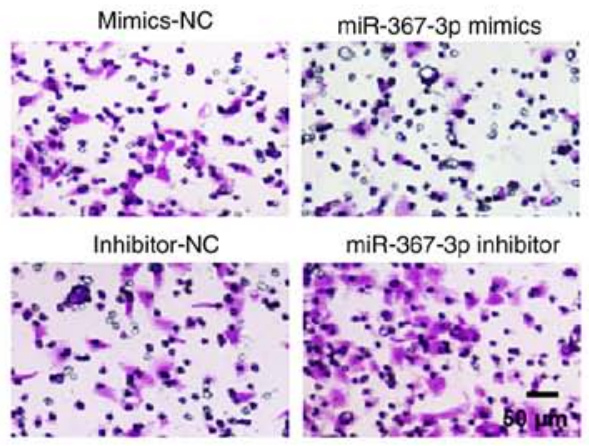

DU145
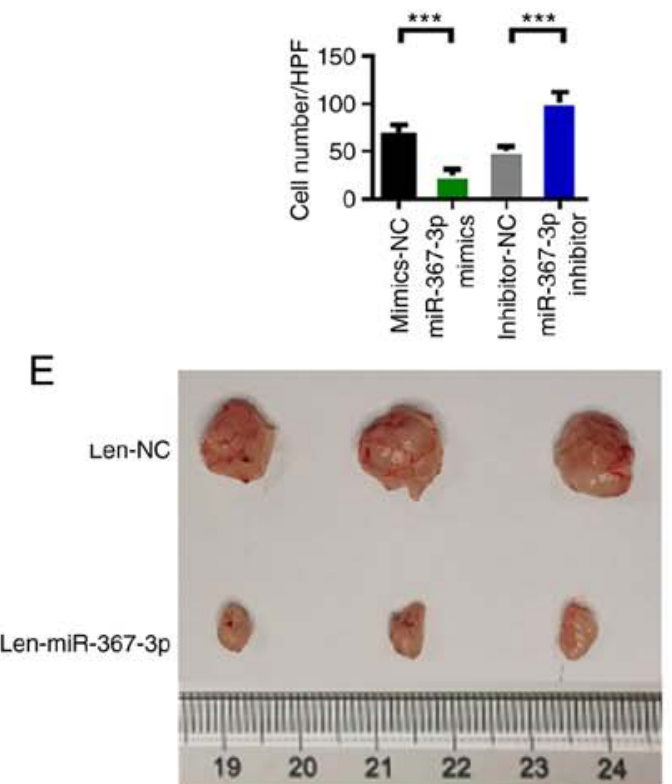

D

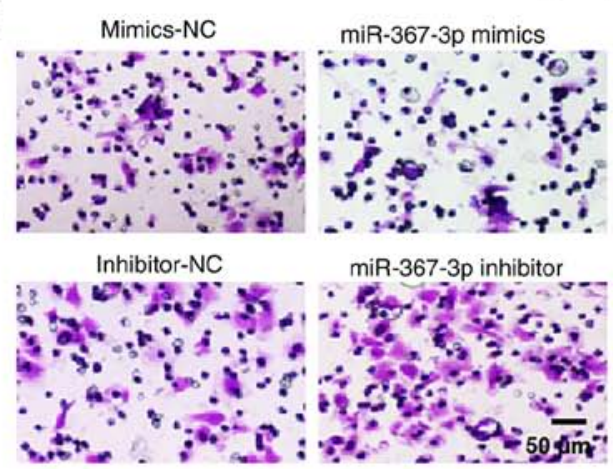

$\mathrm{PC} 3$

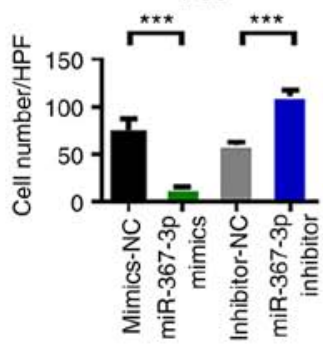

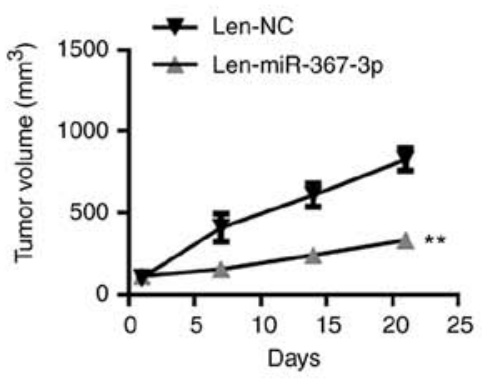

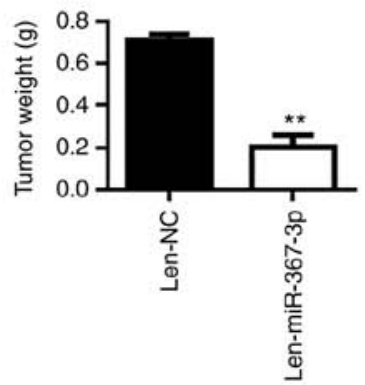

Figure 3. Overexpression of miR-367-3p inhibits the migration, invasion and proliferation of prostate cancer cells. (A) DU145 cell wound healing assay. (B) PC3 cell wound healing assay. (C) DU145 cell Transwell invasion assay. (D) PC3 cell Transwell invasion assay. (E) Animal experiments were performed to verify the antitumor effect of miR-367-3p. ${ }^{*} \mathrm{P}<0.05,{ }^{* *} \mathrm{P}<0.01,{ }^{* * * *} \mathrm{P}<0.001$. Magnification, $\mathrm{x} 200$.

The experimental results showed that siRNA Rab23 reduced the expression of Rab23 (Fig. 5A and B). Subsequently, the proliferation capability of the cells was measured via the BrdU assay. The experimental results showed that Rab23 knockdown inhibited the proliferation of DU145 and PC3 cells (Fig. 5C and D). We performed wound healing experiments to evaluate the migratory capability of prostate cancer cells. The results showed that the knockdown of Rab23 significantly inhibited the migration of DU145 and PC 3 cells (Fig. 5E and F). Subsequently, we conducted the invasion assay to evaluate the invasive capability of prostate cancer cells. We found that the invasive capability of DU145 and PC 3 cells in the Rab23 
A

\begin{tabular}{|lr|}
\hline miR-367-3p WT 5' CAAUUGAAUUACAUUGUGCAAUG 3' & I I I II I I I \\
Rab23 & 3'AGUGGUAACGAUUUCACGUUA 5' \\
I I I I I II I \\
miR-367-3p \\
MT 5' CAAUUGAAUUACAUUCACGUUAG 3'
\end{tabular}

C

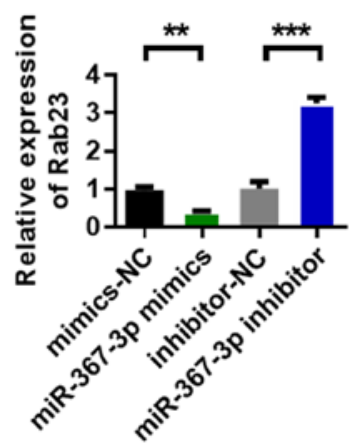

E

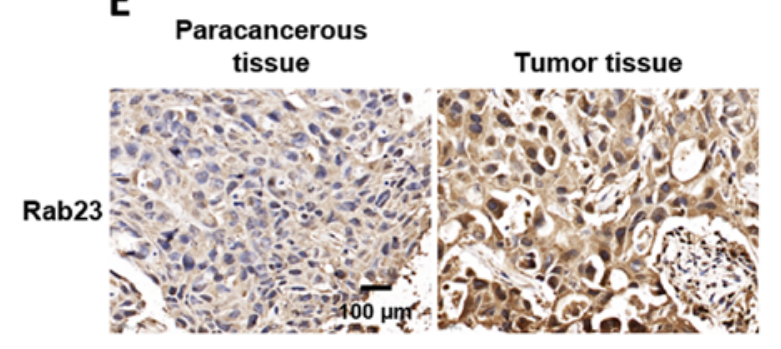

B

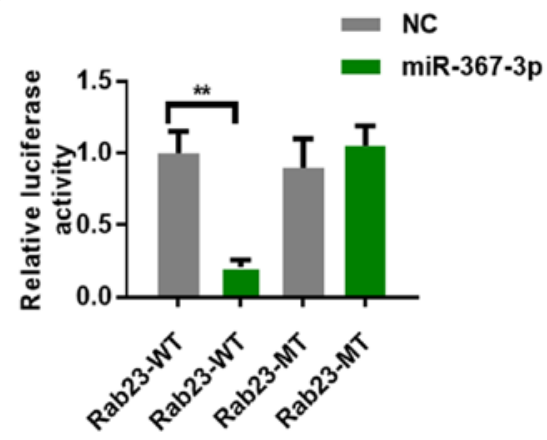

D

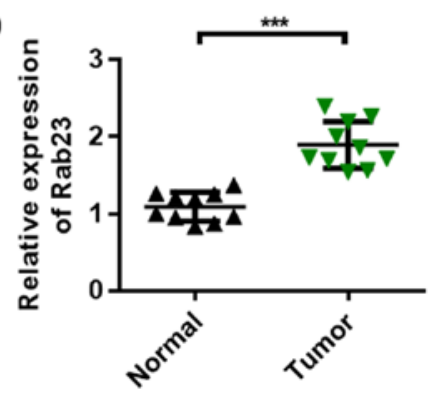

F

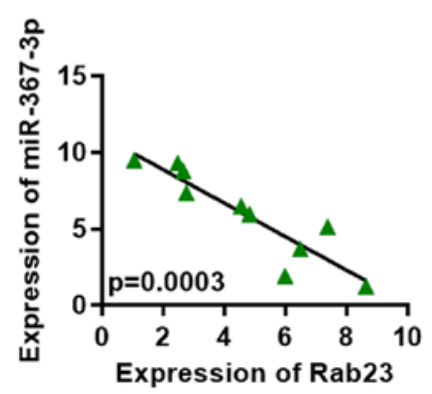

Figure 4. miR-367-3p-targeted Rab23 binding. (A) Image showing miR-367-3p binding sites with Rab23. (B) Double luciferase reporter gene assay demonstrated the binding of miR-367-3p to Rab23 in DU145 cell lines. WT, wild-type; MT, mutated. (C) Cell level confirmed that miR-367-3p overexpression inhibited Rab23 and that miR-367-3p upregulated Rab23. (D) Rab23 is upregulated in prostate cancer tissues. (E) Immunohistochemical detection of Rab23 in paracancer control tissues and tumor tissues. (F) Correlation detection of the coexpression of miR-367-3p and Rab23 in paracancer tumor tissues. ${ }^{* *} \mathrm{P}<0.01$, **** $\mathrm{P}<0.001$.

knockout group was significantly decreased compared with that in the blank control group (Fig. $5 \mathrm{G}$ and $\mathrm{H}$ ).

miR-367-3p downregulates Rab23 expression and inhibits the Hedgehog signaling pathway. Next, we examined the effects of miR-367-3p on the Hedgehog signaling pathway. RT-PCR results showed that Gli1 and Gli2 mRNAs were expressed in the prostate cancer cell lines DU145 and PC3. Expression levels were statistically analyzed in accordance with the ratio of the absorbance value of the amplified products. The expression of Gli1 mRNA in DU145 and PC3 cells was significantly decreased after transfection with miR-367-3p mimics and was statistically different than that in the normal control group (Fig. 6A and B). After transfection with miR-367-3p mimics, the expression of Gli2 mRNA in DU145 and PC3 cells was also significantly decreased (Fig. 6C and D). Changes in the expression levels of Gli1 and Gli2 were detected through western blot analysis and are shown in Fig. 6E. The experimental results showed that miR-367-3p mimics inhibited the expression of Gli1 and Gli2. However, Gli1 and Gli2 were upregulated after treatment with the miR-367-3p inhibitor. The above experimental results indicated that miR-367-3p downregulated Rab23 expression and inhibited the Hedgehog signaling pathway.

Overexpression of Rab23 reverses the anticancer effect of $m i R-367-3 p$. Rab23 was overexpressed, and the anticancer effect of miR-367-3p was analyzed again to validate the interaction between Rab23 and miR-367-3p. First, we detected Rab23 expression in DU145 and PC3 cells. The results of qRT-PCR and western blot analyses showed that miR-367-3p mimics could inhibit the expression of Rab23, whereas Rab23 overexpression could reverse the inhibition of miR-367-3p (Fig. 7A and B). CCK-8 assay results of DU145 and PC3 cells showed that Rab23 overexpression could promote cell proliferation, whereas miR-367-3p mimics could inhibit cell proliferation. The overexpression of Rab23 reversed the miR-367-3p mimic-mediated inhibition of proliferation 
A

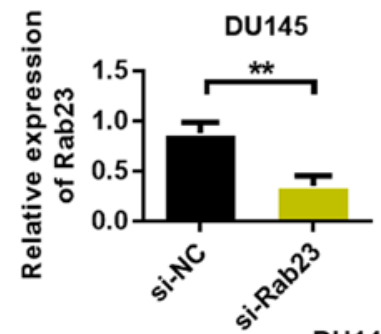

B

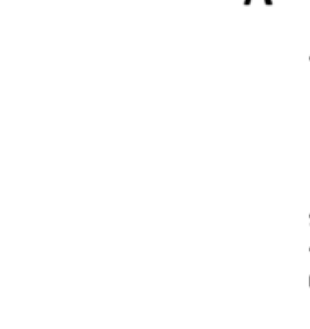

C
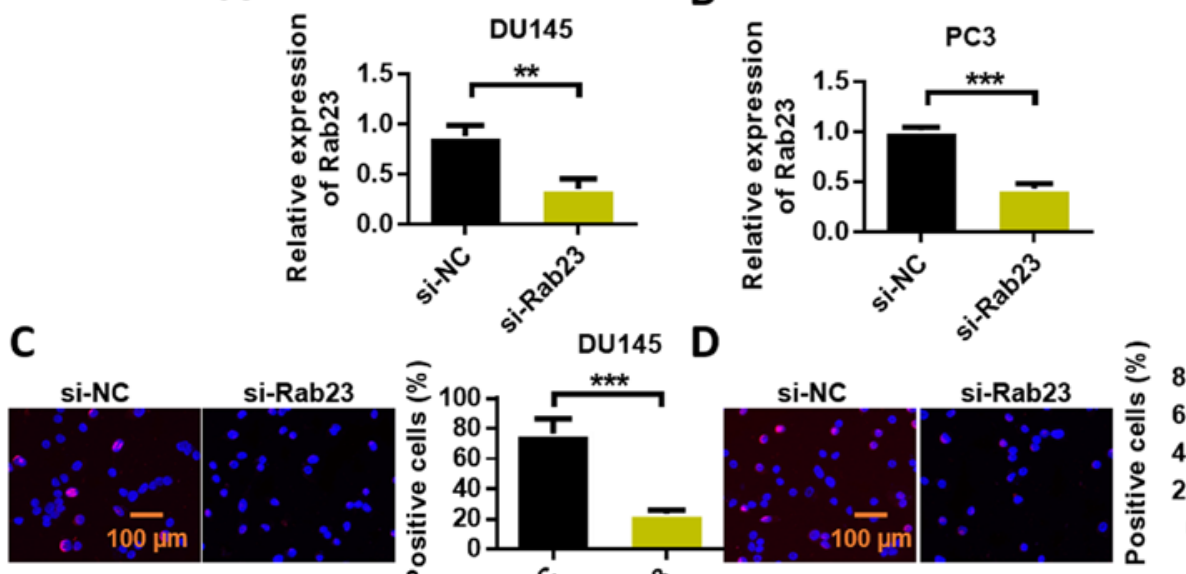

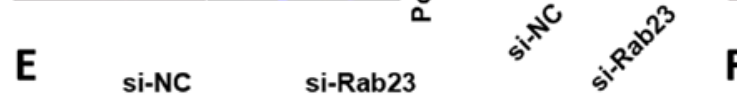
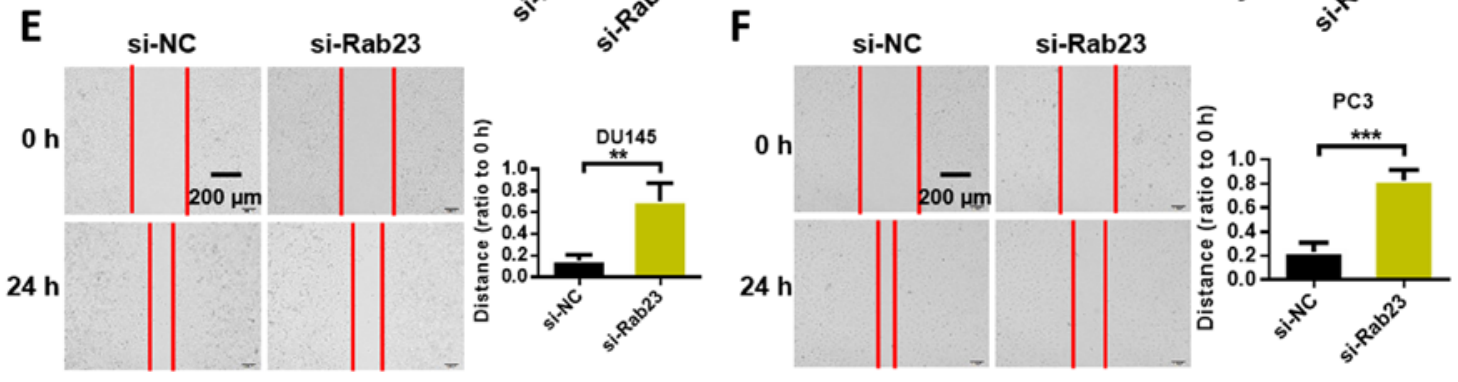

G
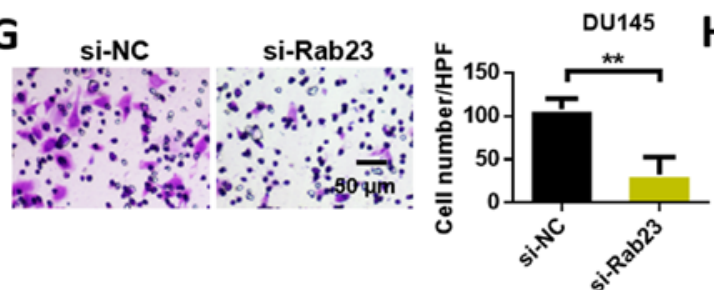

H

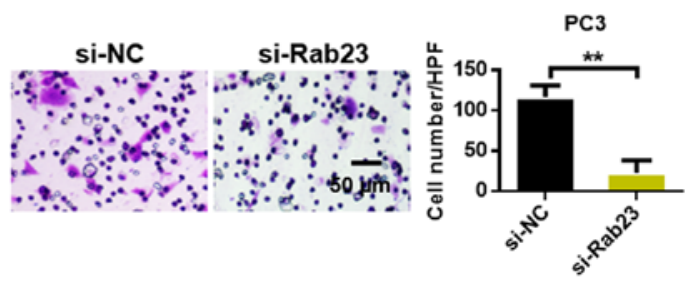

Figure 5. Rab23 knockdown inhibits the malignant evolution of prostate cancer cells. (A) Detection of Rab23 expression in DU145 cells following transfection with sh-NC (negative control) and si-Rab23. (B) Detection of Rab23 expression in PC3 cells following transfection with sh-NC (negative control) and si-Rab23. (C) DU145 cell proliferation via the BrdU assay. (D) PC3 cell proliferation via the BrdU assay. (E) DU145 cell wound healing assay. (F) PC3 cell wound healing assay. (G) DU145 cell invasion assay. (H) PC3 cell invasion assay. ${ }^{* *} \mathrm{P}<0.01,{ }^{* * *} \mathrm{P}<0.001$. Magnification, $\mathrm{x} 200$.

(Fig. 7C and D). The invasion detection results of DU145 and PC3 cells showed that the overexpression of Rab23 could promote cell invasion, whereas miR-367-3p mimics could inhibit cell invasion. Rab23 overexpression reversed the miR-367-3p mimic-mediated inhibition and invasion of the DU145 and PC3 cells (Fig. 7E and F).

\section{Discussion}

MicroRNA (miRNAs/miRs) are short noncoding RNAs that can perform post-transcriptional gene silencing by degrading target genes and inhibiting target gene translation (31-33). The occurrence of malignant tumors is closely related to changes in miRNA expression profiles (34-36). A large number of studies have found that miRNAs play an important regulatory role in the differentiation, apoptosis, metastasis, drug resistance, metabolism, and other biological behaviors of tumor cells (37-40).

miRNAs are associated with the occurrence and development of prostate cancer (41). An in-depth understanding of miRNA regulatory pathways in prostate cancer can improve our understanding of the pathogenesis of this disease. miR-367 is a member of many miRNA families, and the relationship between miR-367 and prostate cancer has been rarely reported. The expression level of miR-367 in non-small cell lung cancer (NSCLC) (42), renal cell carcinoma (43) and other tumor tissues was specifically increased, playing a role in promoting cancer growth. In gastric cancer (44), miR-367 displays low expression and plays a role in cancer inhibition. miR-367 was found to promote tumor growth by inhibiting FBXW7 in NSCLC (45). These results indicate that miR-367 expression patterns and potential effects are different for specific types of tumors.

The present study investigated the effects of miR-367 on the proliferation, invasion and migration of prostate cancer cells as well as the potential mechanisms, aiming to provide a new basis for the application of miR-367 in the diagnosis and treatment of prostate cancer. In this study, we found that the expression of miR-367-3p was down-regulated in prostate cancer tissues. The overexpression of miR-367-3p inhibited the proliferation, invasion, and migration of prostate cancer cells. Inhibition of miR-367-3p promoted the proliferation, migration, and invasion of prostate cancer cells.

We found that Rab23 was highly expressed in prostate cancer tissues and prostate cancer cells. Studies have shown 
A

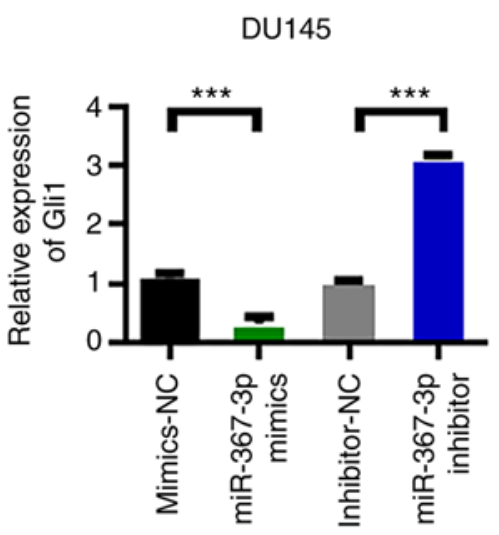

C

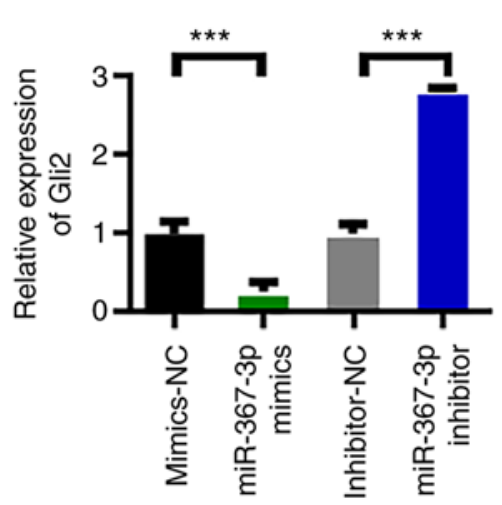

E

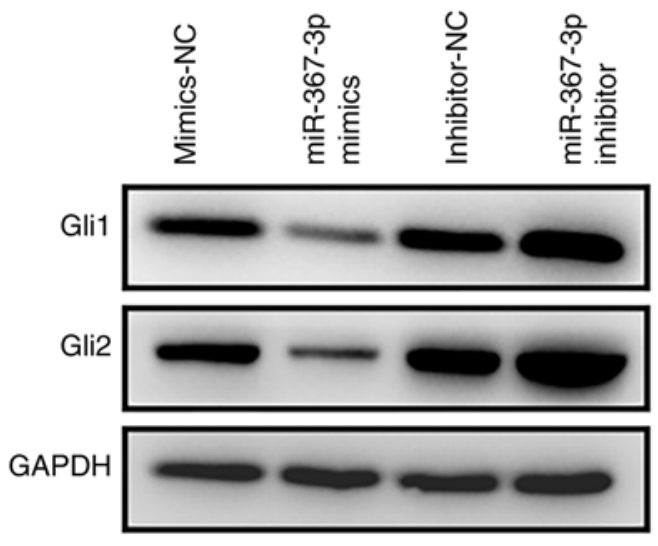

B

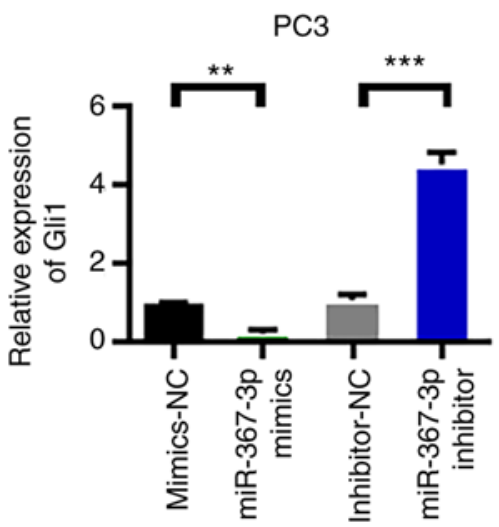

D
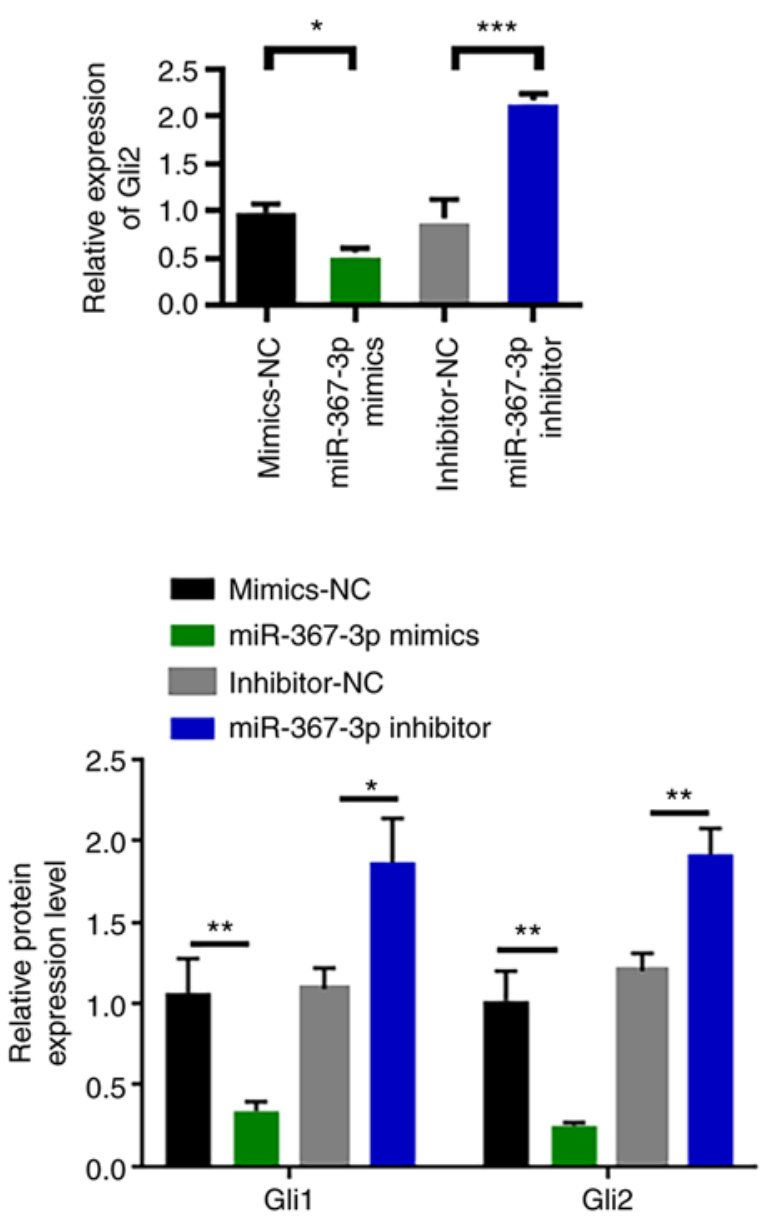

Figure 6. miR-367-3p overexpression downregulates the expression of Rab23 and inhibits the Hedgehog signaling pathway. (A) Detection of Gli1 expression in DU145 cells transfected with the miR-367-3p mimic and inhibitor. (B) Detection of Gli1 expression in PC 3 cells transfected with the miR-367-3p mimic and inhibitor. (C) Detection of Gli2 expression in DU145 cells transfected with the miR-367-3p mimic and inhibitor. (D) Detection of Gli2 expression in PC3 cells transfected with the miR-367-3p mimic and inhibitor. (E) Gli1 and Gli2 expression levels were detected by western blot analysis in DU145 cell lines. ${ }^{*}<0.05$, ${ }^{* *} \mathrm{P}<0.01,{ }^{* * * *} \mathrm{P}<0.001$.

that Rab23 is the downstream target gene of miR-200b. miR-200b was found to act as a tumor-suppressor gene by altering the expression of Rab23 (46). The downstream signaling pathway of Rab23 includes the Hedgehog (Hh) signaling pathway. In recent years, several studies have found that the Hh signaling pathway is closely related to the occurrence and development of tumors. The overactivation of this pathway or the dysfunction of key regulatory factors in this pathway may lead to the excessive or abnormal proliferation of cells, which may eventually lead to the occurrence of tumors (47-49). Hh signaling pathways involve many molecules, such as Smoothened and Gli transcription factors (Gli1, Gli2, and Gli3) (47). In this study, we found that the expression levels of miR-367-3p and Rab23 were negatively correlated. Meanwhile, the overexpression of miR-367-3p significantly inhibited the protein expression of Rab23. 

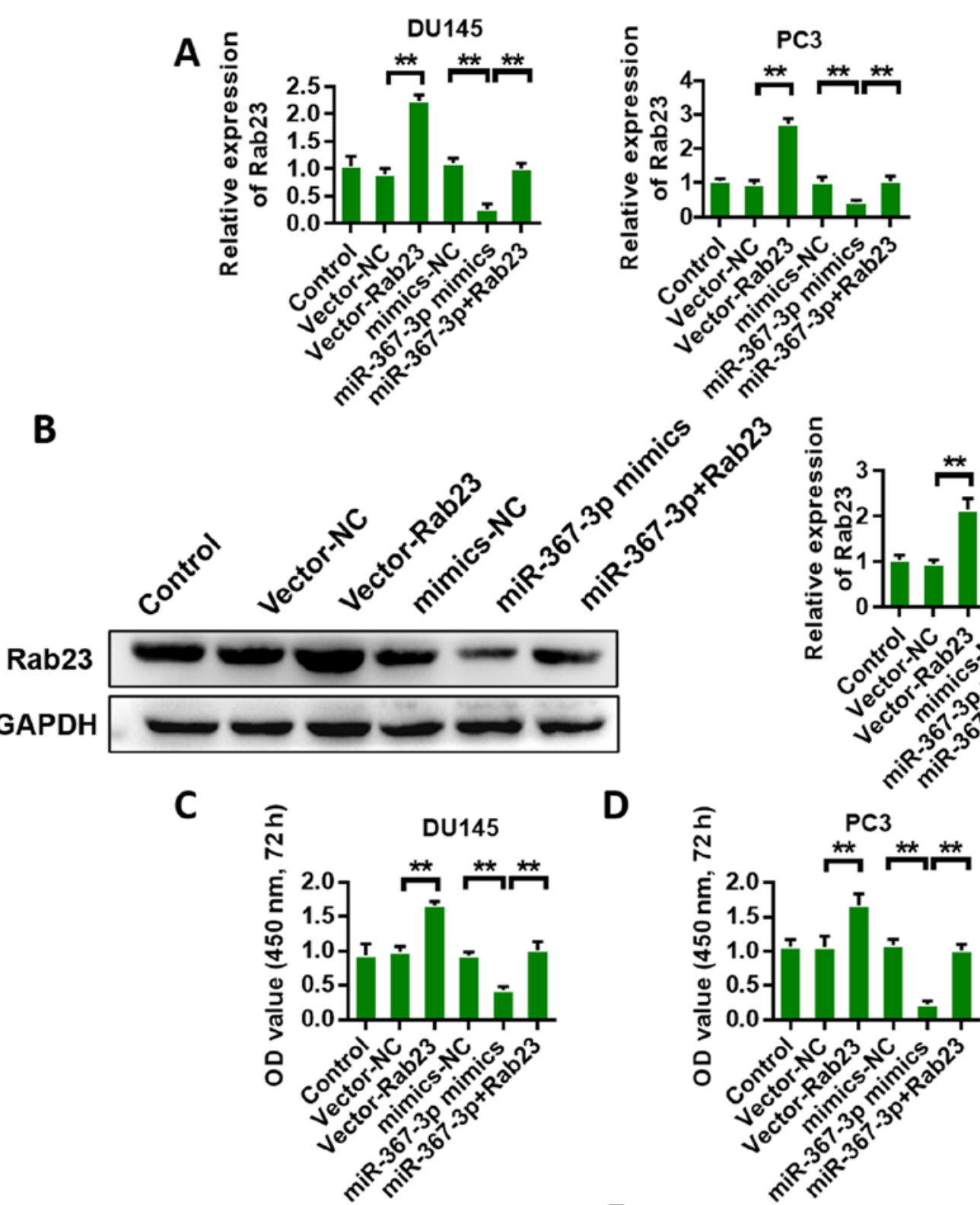

$\mathbf{E}$

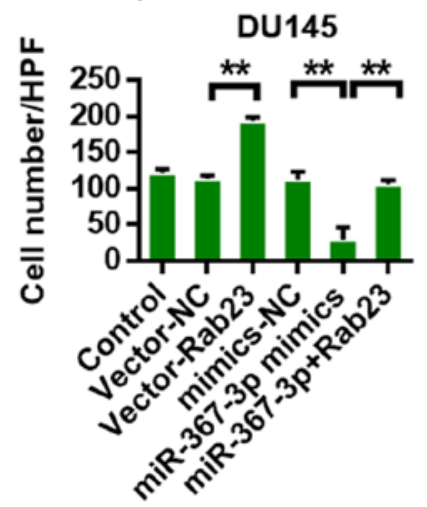

$\mathbf{F}$

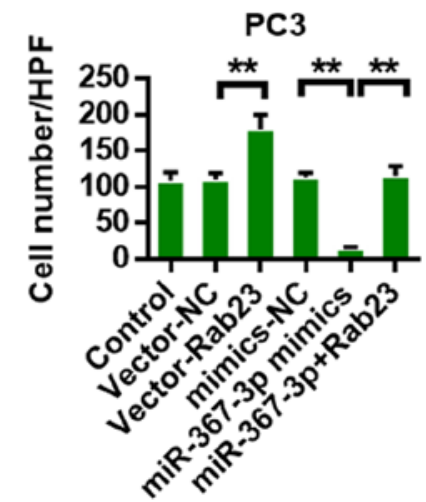

Figure 7. Overexpression of Rab23 reverses the anticancer effect of miR-367-3p. (A) Detection of Rab23 expression in DU145 and PC 3 cells transfected with vector-Rab23 overexpression vector (vector-Rab23), miR-367-3p mimic and both miR-367-3p mimic and vector-Rab23 and the relevant controls. (B) Detection of Rab23 by western blot analysis in the various groups in DU145 cell lines. (C) Detection of DU145 cell proliferation rate by CCK-8 assay. (D) Detection of PC3 cell proliferation rate by CCK-8 assay. (E) DU145 cell Transwell invasion assay. (F) PC3 cell Transwell invasion assay. ${ }^{* *} \mathrm{P}<0.01$.

These results suggest that Rab23 is the target of miR-367-3p. Studies on cell phenotypes showed that when miR-367-3p was upregulated, cell activity was inhibited, and cell invasion and migration capabilities were significantly reduced. At the same time, Rab23 partially reversed the inhibitory effect of miR-367-3p overexpression on cell activity, invasion, and 
migration. The results of this study suggest that miR-367-3p inhibits the malignant phenotype of tumor cells by inhibiting Rab23. We also found that miR-367-3p regulated the expression of Gli1 and Gli2 in the Hh pathway through Rab23. As transcription factors, Gli downstream genes include a variety of genes (cyclin D1 and D2, Hes1, FoxM1, PdgfRa, Igf2, Wnts, and N-Myc) that are related to cell proliferation and differentiation, which may be a key factor leading to tumorigenesis via this pathway (50-55). The gene that maintains cell growth is $\mathrm{Bcl} 2$. Genes that promote cell self-renewal include Bmil and Nanog (56-58). VEGF is an angiogenesis-related gene. Epithelial stromal transformation genes include Snail1, Sip1, Elk1, and Msx2 (59-61) and invasion genes. All these results suggest that miR-367-3p may play an anticancer role by regulating the activation of pathways and the expression of downstream genes.

In conclusion, the expression level of miR-367-3p was found to be decreased in prostate cancer tumor tissues. Further experiments confirmed that Rab23 is a target of miR-367-3p. The overexpression of miR-367-3p inhibited the Hedgehog pathway by inhibiting the expression of Rab23 and finally inhibiting the growth, invasion, and migration of prostate cancer cells. Therefore, miR-367-3p is a new target for the development of drugs for prostate cancer treatment. This study provides a new idea for the development of drugs targeting miR-367-3p for the treatment of prostate cancer.

\section{Acknowledgements}

Not applicable.

\section{Funding}

Funding was provided by the Guangzhou Municipal Science and Technology Program (no. 201804010453).

\section{Availability of data and materials}

The data used to support the findings of this study are available from the corresponding author upon request.

\section{Authors' contributions}

PT participated in the design of this study. WD analyzed and interpreted the data. DL carried out the study and collected important background information. WD and JX carried out literature search, data acquisition, and manuscript editing. All authors read and approved the final manuscript.

\section{Ethics approval and consent to participate}

This study, both for the use of human tissues and animals, was approved by the Ethics Committee of The First Affiliated Hospital of Jinan University (Guangzhou, Guangdong, China) (no. IRB-JN-2019-023). All patients provided signed written informed consent.

\section{Patient consent for publication}

Not applicable.

\section{Competing interests}

The authors declare that they have no competing interests.

\section{References}

1. Nabhan C: Sipuleucel-T immunotherapy for castration-resistant prostate cancer. N Engl J Med 363: 1966-1968, 2010.

2. Schröder FH, Hugosson J, Roobol MJ, Tammela TLJ, Ciatto S, Nelen V, Kwiatkowski M, Lujan M, Lilja H, Zappa M, et al: Screening and prostate-cancer mortality in a randomized European study. N Engl J Med 360: 1320-1328, 2009.

3. Tomlins SA, Rhodes DR, Perner S, Dhanasekaran SM, Mehra R, Sun XW, Varambally S, Cao X, Tchinda J, Kuefer R, et al: Recurrent fusion of TMPRSS2 and ETS transcription factor genes in prostate cancer. Science 310: 644-648, 2005.

4. Tomlins SA, Rhodes DR, Perner S, Dhanasekaran SM, Mehra R, Sun XW, Varambally S, Cao X, Tchinda J, Kuefer R, et al: Recurrent fusion of TMPRSS2 and ETS transcription factor genes in prostate cancer. J Urol 175: 1707, 2006.

5. Raimondi A, Sepe P, Claps M, Maccauro M, Aliberti G, Pagani F, Apollonio G, Randon G, Peverelli G, Seregni E, et al: Safety and activity of radium-223 in metastatic castration-resistant prostate cancer: The experience of Istituto Nazionale dei Tumori. Tumori 106: 406-412, 2020.

6. Pernar CH, Ebot EM, Wilson KM and Mucci LA: The epidemiology of prostate cancer. Cold Spring Harb Perspect Med 8: a030361, 2018.

7. Nelson WG, De Marzo AM and Isaacs WB: Prostate cancer. N Engl J Med 349: 366-381, 2003.

8. Xi X, Liu N, Wang Q, Chu Y, Yin Z, Ding Y and Lu Y: ACT001, a novel PAI-1 inhibitor, exerts synergistic effects in combination with cisplatin by inhibiting PI3K/AKT pathway in glioma. Cell Death Dis 10: 757, 2019.

9. Zhong W, Yang W, Qin Y, Gu W, Xue Y, Tang Y, Xu H, Wang $\mathrm{H}$, Zhang $\mathrm{C}$, Wang $\mathrm{C}$, et al: 6-Gingerol stabilized the p-VEGFR2/VE-cadherin/ $\beta$-catenin/actin complex promotes microvessel normalization and suppresses tumor progression. J Exp Clin Cancer Res 38: 285, 2019.

10. Mahn R, Heukamp LC, Rogenhofer S, Ruecker AV, Müller SC and Ellinger JR: Circulating microRNAs (miRNA) in serum of patients with prostate cancer. Urology 77: 1265.e9-e16, 2011.

11. Xi X, Chu Y, Liu N, Wang Q, Yin Z, Lu Y and Chen Y: Joint bioinformatics analysis of underlying potential functions of hsa-let-7b-5p and core genes in human glioma. J Transl Med 17: 129,2019

12. Kim SJ, Ha JW and Zhang BT: Constructing higher-order miRNA-mRNA interaction networks in prostate cancer via hypergraph-based learning. BMC Syst Biol 7: 47, 2013.

13. Zhu Z, Xu Y, Zhao J, Liu Q, Feng W, Fan J and Wang P: miR-367 promotes epithelial-to-mesenchymal transition and invasion of pancreatic ductal adenocarcinoma cells by targeting the Smad7-TGF- $\beta$ signalling pathway. Br J Cancer 112: 1367-1375, 2015.

14. Campayo M, Navarro A, Viñolas N, Diaz T, Tejero R, Gimferrer JM, Molins L, Cabanas ML, Ramirez J, Monzo M and Marrades R: Low miR-145 and high miR-367 are associated with unfavourable prognosis in resected nonsmall cell lung cancer. Eur Respir J 41: 1172-1178, 2013.

15. Shinde SR and Maddika S: Post translational modifications of Rab GTPases. Small GTPases 9: 49-56, 2018.

16. Prashar A, Schnettger L, Bernard EM and Gutierrez MG: Rab GTPases in immunity and inflammation. Front Cell Infect Microbiol 7: 435, 2017.

17. Solano-Collado V, Rofe A and Spanò S: Rab32 restriction of intracellular bacterial pathogens. Small GTPases 9: 216-223, 2018.

18. Gao Y, Wilson GR, Stephenson SEM, Bozaoglu K, Farrer MJ and Lockhart PJ: The emerging role of Rab GTPases in the pathogenesis of Parkinson's disease. Mov Disord 33: 196-207, 2018.

19. Ortiz-Sandoval CG, Hughes SC, Dacks JB and Simmen T: Interaction with the effector dynamin-related protein 1 (Drp1) is an ancient function of Rab32 subfamily proteins. Cell Logist 4: e986399, 2014.

20. Rybnicek J, Samtleben S, Herrera-Cruz MS and Simmen T: Expression of a T39N mutant Rab32 protein arrests mitochondria movement within neurites of differentiated SH-SY5Y cells. Small GTPases 11: 289-292, 2020. 
21. Haile Y, Deng X, Ortiz-Sandoval C, Tahbaz N, Janowicz A Lu JQ, Kerr BJ, Gutowski NJ, Holley JE, Eggleton P, et al: Rab32 connects ER stress to mitochondrial defects in multiple sclerosis. J Neuroinflammation 14: 19, 2017.

22. Lin Z, Li JW, Wang Y, Chen T, Ren N, Yang L, Xu W, He H, Jiang Y, Chen X, et al: Abnormal miRNA-30e expression is associated with breast cancer progression. Clin Lab 62: 121-128, 2016.

23. Shibata D, Mori Y, Cai K, Zhang L, Yin J, Elahi A, Hamelin R, Wong YF, Lo WK, Chung TK, et al: RAB32 hypermethylation and microsatellite instability in gastric and endometrial adenocarcinomas. Int J Cancer 119: 801-806, 2006.

24. Alexandratou E, Yova D, Gorpas D, Maragos P, Agrogiannis G and Kavantzas N: Texture analysis of tissues in Gleason grading of prostate cancer. Int Soc Opt Photon 6859: 685904, 2008.

25. Ozkan TA, Eruyar AT, Cebeci OO, Memik O, Ozcan L and Kuskonmaz I: Interobserver variability in Gleason histological grading of prostate cancer. Scand J Urol 50: 420-424, 2016

26. Francisco JS, Moraes HP and Dias EP: Evaluation of the Image-Pro Plus 4.5 software for automatic counting of labeled nuclei by PCNA immunohistochemistry. Braz Oral Res 18: 100-104, 2004.

27. Zhong W, Hou H, Liu T, Su S, Xi X, Liao Y, Xie R, Jin G, Liu X, Zhu L, et al: Cartilage oligomeric matrix protein promotes epithelial-mesenchymal transition by interacting with transgelin in colorectal cancer. Theranostics 10: 8790-8806, 2020.

28. Livak KJ and Schmittgen TD: Analysis of relative gene expression data using real-time quantitative PCR and the 2(-Delta Delta C(T))method. Methods 25: 402-408, 2001.

29. Ong MHA and Puteh F: Quantitative data analysis: Choosing between SPSS, PLS, and AMOS in social science research. Int Interdiscip J Sci Res 3: 14-25, 2017.

30. Zhong W, Sun B, Gao W, Qin Y, Zhang H, Huai L, Tang Y, Liang Y, He L, Zhang X, et al: Salvianolic acid A targeting the transgelin-actin complex to enhance vasoconstriction. EBioMedicine 37: 246-258, 2018.

31. Kantoff PW, Higano CS, Shore ND, Berger ER, Small EJ, Penson DF, Redfern CH, Ferrari AC, Dreicer R, Sims RB, et al: Sipuleucel-T immunotherapy for castration-resistant prostate cancer. N Engl J Med 363: 411-422, 2010.

32. Collins AT, Berry PA, Hyde C, Stower MJ and Maitland NJ: Prospective identification of tumorigenic prostate cancer stem cells. Cancer Res 65: 10946-10951, 2005.

33. Chen J, Shu K, Yao J, et al: Is it necessary to perform pelvic lymph node dissection in patients with high-and very high-risk prostate cancer treated with radical prostatectomy? -a retrospective single-center study. J Clin Urol (in Chinese) 2018. https://xueshu. baidu.com/usercenter/paper/show? paperid=9a69f7a8534cf198bf f20528e96f7190\&site=xueshu_se.

34. Zhang W, Zang J, Jing X, Sun Z, Yan W, Yang D, Shen B and Guo F: Identification of candidate miRNA biomarkers from miRNA regulatory network with application to prostate cancer. J Transl Med 12: 66, 2014

35. Schaefer A, Jung M, Miller K, Lein M, Kristiansen G, Erbersdobler A and Jung K: Suitable reference genes for relative quantification of miRNA expression in prostate cancer. Exp Mol Med 42: 749-758, 2010

36. Sanders I, Holdenrieder S, Walgenbach-Brünagel G, von Ruecker A, Kristiansen G, Müller SC and Ellinger J: Evaluation of reference genes for the analysis of serum miRNA in patients with prostate cancer, bladder cancer and renal cell carcinoma. Int J Urol 19: 1017-1025, 2012.

37. Mikolajczyk SD, Catalona WJ, Evans CL, Linton HJ, Millar LS, Marker KM,Katir K, Amirkhan A and Rittenhouse HG: Proenzyme forms of prostate-specific antigen in serum improve the detection of prostate cancer. Clin Chemistry 50: 1017-1025, 2004.

38. Messina M, Kucuk O and Lampe JW: An overview of the health effects of isoflavones with an emphasis on prostate cancer risk and prostate-specific antigen levels. J AOAC Int 89: 1121-1134, 2006

39. Tímár J: Molecular pathology of prostate cancer. Magy Onkol 63: 5-9, 2019 (In Hu)

40. Xiao T, Zhong W, Zhao J, Qian B, Liu H, Chen S, Qiao K, Lei Y, Zong S, Wang H, et al: Polyphyllin I suppresses the formation of vasculogenic mimicry via Twist1/VE-cadherin pathway. Cell Death Dis 9: 906, 2018

41. Majid S, Dar AA, Saini S, Shahryari V, Arora S, Zaman MS Chang I, Yamamura S, Tanaka Y, Chiyomaru T, et al: miRNA-34b inhibits prostate cancer through demethylation, active chromatin modifications, and AKT pathways. Clin Cancer Res 19: 73-84, 2013.
42. Xu J, Wu W, Wang J, Huang C, Wen W, Zhao F, Xu X, Pan X, Wang W, Zhu Q and Chen L: miR-367 promotes the proliferation and invasion of non-small cell lung cancer via targeting FBXW7. Oncol Rep 37: 1052-1058, 2017.

43. Ding D, Zhang Y, Wen L, Fu J, Bai X, Fan Y, Lin Y, Dai H, Li Q, Zhang Y and An R: miR-367 regulates cell proliferation and metastasis by targeting metastasis-associated protein 3 (MTA3) in clear-cell renal cell carcinoma. Oncotarget 8: 63084-63095, 2017.

44. Bin Z, Dedong H, Xiangjie F, Hongwei X and Qinghui Y: The microRNA-367 inhibits the invasion and metastasis of gastric cancer by directly repressing Rab23. Genet Test Mol Biomarkers 19: 69-74, 2015.

45. Xiao G, Gao X, Sun X, Yang C, Zhang B, Sun R, Huang G, Li X, Liu J, Du N, et al: miR-367 promotes tumor growth by inhibiting FBXW7 in NSCLC. Oncol Rep 38: 1190-1198, 2017.

46. Liu Q, Tang H, Liu X, Liao Y, Li H, Zhao Z, Yuan X and Jiang W: miR-200b as a prognostic factor targets multiple members of RAB family in glioma. Med Oncol 31: 859, 2014.

47. Lin EH, Kao YR, Lin CA, Kuo TY, Yang SP, Hsu CF, Chou TY, $\mathrm{Ho} \mathrm{CC}$ and $\mathrm{Wu} \mathrm{CW}$ : Hedgehog pathway maintains cell survival under stress conditions, and drives drug resistance in lung adenocarcinoma. Oncotarget 7: 24179-24193, 2016.

48. Harris LG, Pannell LK, Singh S, Samant RS and Shevde LA: Increased vascularity and spontaneous metastasis of breast cancer by hedgehog signaling mediated upregulation of cyr61. Oncogene 31: 3370-3380, 2012.

49. Atwood SX, Li M, Lee A, Tang JY and Oro AE: GLI activation by atypical protein kinase $C \mathrm{t} / \lambda$ regulates the growth of basal cell carcinomas. Nature 494: 484-488, 2013.

50. Dahmane N, Lee J, Robins P, Heller P and Ruiz I Altaba A: Activation of the transcription factor Gli1 and the Sonic hedgehog signalling pathway in skin tumours. Nature 389: 876-881, 1997.

51. Kenney AM and Rowitch DH: Sonic hedgehog promotes G(1) cyclin expression and sustained cell cycle progression in mammalian neuronal precursors. Mol Cell Biol 20: 9055-9067, 2000.

52. Mullor JL, Dahmane N, Sun T and Ruiz I Altaba A: Wnt signals are targets and mediators of Gli function. Curr Biol 11: 769-773, 2001.

53. Teh MT, Wong ST, Neill GW, Ghali LR, Philpott MP and Quinn AG: FOXM1 is a downstream target of Gli1 in basal cell carcinomas. Cancer Res 62: 4773-4780, 2002.

54. Kenney AM, Cole MD and Rowitch DH: Nmyc upregulation by sonic hedgehog signaling promotes proliferation in developing cerebellar granule neuron precursors. Development 130: 15-28, 2003.

55. Ingram WJ, McCue KI, Tran TH, Hallahan AR and Wainwright BJ: Sonic Hedgehog regulates Hes1 through a novel mechanism that is independent of canonical Notch pathway signalling. Oncogene 27: 1489-1500, 2008.

56. Leung C, Lingbeek M, Shakhova O, Liu J, Tanger E, Saremaslani P, Van Lohuizen M and Marino S: Bmil is essential for cerebellar development and is overexpressed in human medulloblastomas. Nature 428: 337-341, 2004.

57. Clement V, Sanchez P, de Tribolet N, Radovanovic I and Ruiz I Altaba A: HEDGEHOG-GLI1 signaling regulates human glioma growth, cancer stem cell self-renewal, and tumorigenicity. Curr Biol 17: 165-172, 2007.

58. Stecca B and Ruiz i Altaba A: A GLI1-p53 inhibitory loop controls neural stem cell and tumour cell numbers. EMBO J 28: 663-676, 2009

59. Li Y, Zhang H, Litingtung $\mathrm{Y}$ and Chiang C: Cholesterol modification restricts the spread of Shh gradient in the limb bud. Proc Natl Acad Sci USA 103: 6548-6553, 2006.

60. Ohta H, Aoyagi K, Fukaya M, Danjoh I, Ohta A, Isohata N, Saeki N, Taniguchi H, Sakamoto H, Shimoda T, et al: Cross talk between hedgehog and epithelial-mesenchymal transition pathways in gastric pit cells and in diffuse-type gastric cancers. Br J Cancer 100: 389-398, 2009.

61. Varnat F, Duquet A, Malerba M, Zbinden M, Mas C, Gervaz P and Ruiz i Altaba A: Human colon cancer epithelial cells harbour active HEDGEHOG-GLI signalling that is essential for tumour growth, recurrence, metastasis and stem cell survival and expansion. EMBO Mol Med 1: 338-351, 2009.

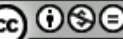

This work is licensed under a Creative Commons Attribution-NonCommercial-NoDerivatives 4.0 International (CC BY-NC-ND 4.0) License. 